\title{
Desigualdade de Gênero e Escuta Psi de Mulheres Atendidas na Atenção Básica
}

\author{
Marina Haase da Costa Franco ${ }^{1}$ \\ ${ }^{1}$ Grupo Hospitalar Conceição, \\ RS, Brasil. \\ Ananyr Porto Fajardo ${ }^{1}$ \\ ${ }^{1}$ Grupo Hospitalar Conceição, RS, Brasil.
}

\author{
Priscila Abrahão Pereira Cardoso² \\ ${ }^{2}$ Associação Intercomunitária de \\ Atendimento Social, RS, Brasil. \\ Eliana Dable de Mello $^{3}$ \\ ${ }^{3}$ Instituto APPOA, RS, Brasil.
}

Resumo: Este estudo tem como objetivo investigar o que psicólogos na atenção básica de Porto Alegre identificam como necessidades em saúde mental das mulheres atendidas, buscando verificar se sua escuta profissional permite estabelecer nexos entre o sofrimento psíquico e a desigualdade de gênero vivenciada pelas usuárias. Em 2017, foi realizado grupo focal com nove psicólogas que atuam em unidades de Saúde da Família, em que foi construída coletivamente uma narrativa segundo o método de Grupo Focal Narrativo. Constituem a narrativa final oito núcleos argumentais: "Sofrimento mascarado"; "Os homens também sofrem com isso"; "Várias gerações de mulheres cuidadoras"; "Aquele desejo de constituir uma família a qualquer custo"; "Por que o homem acha que pode usar uma mulher como se fosse um objeto?"; "Maternidade compulsória"; "Novas formas de exercício da sexualidade"; e "O hospital tomou como uma afronta o empoderamento da mulher". Considera-se que o estudo proporcionou às participantes um espaço de reflexão coletiva sobre si mesmas e suas práticas.

Palavras-chave: Gênero e Saúde, Psicologia, Saúde Pública, Atenção Primária à Saúde, Mulheres.

\section{Gender Inequality and Psychological Listening of Women Attended in Primary Healthcare}

\begin{abstract}
This study aims to investigate the mental health need of female patient as to psychologists working in primary healthcare services in Porto Alegre - Brazil, verifying whether their psychological listening establishes associations between the psychological suffering and gender inequality experienced by the users. Based on a Narrative Focus Group methodology, a focus group with nine psychologists from Family Health services was conducted in 2017. The final narrative consists of eight argumentative nuclei: "masked suffering," "men also suffer from this," "several generations of female caregivers," "that desire to set up a family at any cost," "why do men think they can use a woman as if she were an object?," "compulsory maternity", "new ways of exercising sexuality," and "the hospital took woman's empowerment as an affront." This study provided participants a space for collectively reflecting on themselves and on their practices.
\end{abstract}

Keywords: Gender and Health, Psychology, Public Health, Primary Health Care, Women.

\section{Desigualdad de Género y Escucha de Mujeres que Procuran Atención Primaria}

Resumen: Este estudio tiene como objetivo conocer lo que los psicólogos en la atención primaria de Porto Alegre (Brasil) identifican como necesidades en salud mental de las mujeres 
que procuran atención, con el fin de verificar si su escucha profesional posibilita establecer nexos entre el sufrimiento psíquico y la desigualdad de género vivida por las usuarias. En el 2017, se realizó un grupo focal con nueve psicólogas que actúan en Unidades de Salud Familiar y se construyó colectivamente una narrativa conforme al método de grupo focal narrativo. Ocho núcleos argumentales constituyeron la narrativa final: "Sufrimiento enmascarado"; "Los hombres también sufren con eso"; "Varias generaciones de mujeres cuidadoras"; "La intención de constituir una familia sin importar el costo"; “¿Por qué el hombre cree que puede usar a una mujer como un objeto?"; "Maternidad obligatoria"; "Nuevas formas de ejercicio de la sexualidad"; y "El hospital cree ser una afrenta el empoderamiento femenino". Se considera que el grupo focal proporcionó a las participantes un espacio de reflexión colectiva acerca de sí mismas y de sus prácticas.

Palabras clave: Género y Salud, Psicología, Salud Pública, Atención Primaria de Salud, Mujeres.

\section{Introdução}

Desigualdades sociais em saúde têm sido documentadas há muito tempo, principalmente a partir do século XIX, e se referem a diferenças no estado de saúde entre grupos definidos por características sociais (Barata, 2009). A versão brasileira da teoria da determinação social do processo saúde-doença dá maior ênfase explicativa ao modo de vida, um conceito que engloba tanto aspectos materiais quanto simbólicos, reunindo em um mesmo marco teórico as condições coletivas dos grupos e os comportamentos de seus indivíduos. Ao comparar situações, não se atribui necessariamente um juízo de valores àquilo que é desigual, porém,

quando falamos em desigualdade social geralmente estamos nos referindo a situações que implicam algum grau de injustiça, ... porque estão associadas a características sociais que sistematicamente colocam alguns grupos em desvantagem com relação à oportunidade de ser e se manter sadio (Barata, 2009, p. 11-12).

Nessa perspectiva, a desigualdade de gênero consta como um dos determinantes sociais em saúde, visto que as relações de gênero têm dinâmica própria e atravessam todas as dimensões da vida pública e privada. Ainda que interaja com outras categorias macrossociais relativas a classe social, idade, raça e etnia, escolarização, condições de trabalho e de moradia, Barata (2009) observa o efeito independente da condição de gênero sobre o estado de saúde, inclusive no que diz respeito a "distúrbios psiquiátricos menores" (p. 85).
Conceitualmente, gênero é uma construção cultural baseada nas diferenças percebidas entre os sexos masculino e feminino. Nesse sentido, em uma cultura binária, o processo de se tornar mulher ou se tornar homem é descrito por Butler (1990, p. 300) como "obrigar o corpo a conformar-se com uma idéia histórica” do que é uma mulher ou um homem. A ideia de identidade de gênero, contudo, é desconstruída pela autora, que conceitualiza gênero enquanto performance, isto é, uma identidade debilmente construída no tempo, instituída por uma repetição estilizada de atos. Com essa repetição, a performance aos poucos se cristaliza e passa a emanar uma ideia - equivocada - de substancialização. Visto que essa repetição estilizada de atos se produz mediante coação social, que geralmente é punitiva, a normatividade de gênero configura uma violência estrutural. Além disso, o gênero hierarquiza homens e mulheres, bem como os valores associados a cada um deles em nossa cultura, estruturando relações de poder e dominação; portanto, aquela violência da qual pode padecer qualquer mulher pelo mero fato de ser mulher, isto é, de pertencer a essa categoria social, identifica-se como "violência de gênero" (Negrão, Vargas, \& Rodrigues, 2015, p. 85). Segundo Zanello, Fiuza e Costa (2015),

o sofrimento (e a reação a ele) é construído socialmente e moldado segundo os valores e ideais estereotipados de gênero, havendo caminhos privilegiados (porém não excludentes) de subjetivação (distintos) para homens e mulheres, os quais se tornam evidentes na expressão do adoecimento psíquico. . . aquilo que parece ser algo extremamente individual, ou seja, a vivência de 
um conjunto de mal-estares no âmbito subjetivo, expressa regularidades que são moldadas por uma dada configuração social (p. 239).

Assim, vivências de sofrimento psíquico e emocional (que, muitas vezes, permanecem aquém dos diagnósticos) apresentam-se de forma gendrada, isto é, são reveladoras da condição de gênero da pessoa e da violência estrutural naquela comunidade. As necessidades de saúde das mulheres envolvem processos de produção de saúde, adoecimento e cuidado relacionados ao lugar historicamente construído para elas, aos modelos de atenção em saúde associados a ele, a suas condições de vida cotidiana e aos modos de resistência utilizados a fim de dar conta de condições opressivas.

Quando um usuário acessa um serviço de saúde, espera de seus trabalhadores uma ação que resolva, ou ao menos mitigue, o problema que o levou àquele serviço. O resultado dessa ação, reconhecida como resposta àquela necessidade, reitera o que o usuário precisará consumir em situação semelhante, bem como onde o buscará. Schraiber e Mendes-Gonçalves (1996) apontam a circularidade entre as necessidades e o processo de trabalho na oferta e demanda em saúde; para eles, as ações em saúde representam "não apenas resposta a necessidades mas, imediatamente, contexto instaurador de necessidades" (p. 30). Responder às necessidades de saúde, portanto, "deveria significar implementar ações que incidissem nos determinantes, e não só na doença, que já é o resultado do desgaste expresso no corpo biopsíquico individual" (Campos \& Bataiero, 2007, p. 606).

Conforme o modo como os sistemas de saúde organizam suas práticas para responder às necessidades de saúde, "há sistemas que potencializam as desigualdades existentes na organização social e outros que procuram compensar, pelo menos em parte, os resultados danosos da organização social sobre os grupos socialmente mais vulneráveis" (Barata, 2009, p. 20). Entre os princípios do Sistema Único de Saúde (SUS), está o de equidade, que prevê atendimento a cada indivíduo ou população de acordo com suas respectivas necessidades. Segundo Barata (2009, p. 94), "a equidade de gênero não implica a igualdade entre homens e mulheres, seja no estado de saúde, seja no consumo de serviços de saúde, mas o atendimento equitativo das necessidades de homens e mulheres".
Nesse sentido, para que a atenção à saúde seja equitativa, são fundamentais as "tecnologias de conversa” (Teixeira, 2005, p. 592) na identificação, elaboração e negociação com os usuários das necessidades que podem vir a ser satisfeitas em determinado serviço de saúde ou em outros espaços institucionais. Válido para todo o campo da saúde, isso é ainda mais evidente na saúde mental e na prática do psicólogo, nas quais os recursos terapêuticos são eminentemente relacionais e conversacionais - as chamadas “tecnologias leves" (Merhy, 2002).

Para que o SUS não potencialize a desigualdade de gênero existente em nossa organização social e possa operar no sentido de compensar seus resultados danosos por meio do trabalho na saúde pública, há escolhas a serem feitas desde o âmbito macropolítico da gestão do poder público até o micropolítico, inclusive quanto aos aspectos mais sutis de um atendimento em unidade de saúde, por exemplo. Dada a necessidade de investir em tecnologias leves, esta pesquisa visa contribuir possibilitando uma reflexão sobre as necessidades em saúde mental das mulheres e o papel da psicologia nesse processo de saúde, adoecimento e cuidado.

No escopo da saúde pública brasileira, a atenção básica tem se tornado um campo privilegiado para as intervenções no âmbito da saúde mental, em virtude do foco territorial de suas ações, da integralidade e da longitudinalidade do cuidado. Diversas necessidades em saúde mental são identificadas por profissionais das equipes de Unidades Básicas de Saúde (UBS) e da Estratégia de Saúde da Família (ESF), bem como pelos agentes comunitários de saúde. Para responder a tais necessidades, o investimento na atenção básica visa oferecer ações diversificadas e ricas em possibilidades, em redes intersetoriais e de apoio social, demonstrando grande potencialidade terapêutica e de produção de vida dos sujeitos e, ainda, evitando a utilização desnecessária de recursos assistenciais mais complexos.

A rede de atenção básica de Porto Alegre conta com 143 unidades de saúde (Prefeitura Municipal de Porto Alegre, 2019). O campo delimitado para esta pesquisa foi de 12 unidades de saúde da família nas regiões de saúde do município citado, denominadas Norte/Eixo Baltazar e Leste/Nordeste, cujas equipes multidisciplinares incluem pelo menos um profissional psicólogo. Nesse contexto, as práticas psi incluem o acompanhamento direto e indireto dos casos, por meio de atendimentos individuais e coletivos, visitas domiciliares, discussões de caso em equipe, articulação com 
a rede intersetorial e supervisão de psicólogos residentes e estagiários de psicologia. Portanto, esse profissional se encontra em uma posição privilegiada de saber sobre o sofrimento psíquico de mulheres de todas as faixas etárias, bem como de seus modos de vida.

Assim, este estudo investiga o que os psicólogos da atenção básica identificam como necessidades em saúde mental das mulheres atendidas, buscando verificar se sua escuta profissional permite estabelecer nexos entre o sofrimento psíquico e a desigualdade de gênero vivenciada pelas usuárias. A escolha metodológica visa também contribuir para a qualificação da atenção ao proporcionar um espaço de discussão e reflexão. Os efeitos da pesquisa-intervenção foram abordados em outra produção (Franco, Farajado, \& Mello, 2020).

\section{Método}

Este estudo se caracteriza como qualitativo, de abordagem exploratória, com um desenho participativo que, ao intervir no universo pesquisado, propicia o fortalecimento de seus próprios agentes. O grupo focal como técnica de coleta de dados, segundo Miranda, Figueiredo, Ferrer e Onocko-Campos (2008),

... parte de encontros grupais entre pessoas que compartilham traços comuns. Caracteriza-se pelo interesse nos conhecimentos, opiniões, representações, atitudes e valores dos participantes sobre uma questão específica. Em geral, tais informações são mais facilmente captadas durante um processo de interação em que comentários de uns podem fazer emergir a opinião de outros. . Com isso, é possível atingir um número maior de pessoas ao mesmo tempo e obter, com alguma facilidade, dados com certo nível de profundidade em um período curto de tempo (Miranda et al., 2008, p. 250).

Para composição do grupo focal (amostra intencional e homogênea), foram convidadas doze psicólogas, das quais nove participaram, totalizando de cinco a oito participantes em cada encontro. Foi utilizado o espaço já existente de reunião periódica das participantes. Os encontros, com duração aproximada de uma hora cada, foram gravados em áudio e transcritos na íntegra.

O Grupo Focal Narrativo (Onocko-Campos, 2011) é composto de dois momentos. No primeiro encontro, questões abertas disparam a discussão, que neste caso foram: a) Quais são os problemas ou necessidades em saúde mental das mulheres atendidas na atenção básica?; e b) Existe relação entre as necessidades apresentadas e a desigualdade de gênero? Após um mês, foi realizada a segunda rodada do grupo focal, denominada grupo (ou momento) hermenêutico, em que a narrativa do primeiro encontro é apresentada e discutida com o coletivo para que o grupo possa se apropriar da produção, validar os dados e aprofundar temas pouco desenvolvidos na primeira sessão. A partir da necessidade de mais tempo constatada pelo próprio grupo, acordou-se que o segundo momento seria concluído em um terceiro encontro, no mês seguinte. A narrativa foi construída de forma conjunta entre a pesquisadora principal e grupo participante durante os três encontros e finalizada no grupo de pesquisa, que a codificou por meio de núcleos argumentais. Conforme Onocko-Campos (2011),

Um núcleo argumental é um conjunto de frases que não somente se referem a um tema, também tenta atribuir a ele algum tipo de explicação. Explicação no sentido de um porquê, de um para quê e de um como. Os núcleos argumentais não são os temas levantados, porém a "tessitura da intriga” sobre esses temas (p. 1278).

Seguindo a Resolução no 466 (2012), o estudo foi avaliado e aprovado pelo Comitê de Ética em Pesquisa do Hospital Nossa Senhora da Conceição do Grupo Hospitalar Conceição - CEP/GHC (CAAE: 62231616.8.0000.5530 / No do parecer: 1.890.444).

\section{Resultados e discussão}

O grupo focal, ao narrar as necessidades em saúde mental das mulheres atendidas nas unidades de saúde, identificou efeitos da desigualdade de gênero nos processos de produção de saúde-adoecimento-cuidado. A narrativa a seguir visa demonstrar como o coletivo pesquisado percebe essa relação, a partir de núcleos argumentais nomeados com termos e expressões utilizados pelo grupo e selecionados pelas autoras.

\section{"Sofrimento mascarado"}

A partir de sua atuação, as psicólogas identificaram, desde o primeiro encontro, diversos sofrimentos e violências associados à divisão social dos papéis de 
gênero e sua naturalização. Frente à proposta de pensar o sofrimento individual relacionando-o à questão de gênero, que é da ordem da cultura e, portanto, do coletivo, refletiram:

... na comunidade que eu atendo, que muitas das pessoas vêm de uma história, tanto na sua geração ou na geração anterior, de ter tido uma vivência no campo, onde a divisão social das tarefas estava muito estabelecida entre o que é papel da mulhere do homem. . . uma cultura ainda muito centrada na figura masculina. . em que a mulher assume papéis de cuidado e tarefas domésticas e tal - e acho que, em situações de violência, isso se mostra mais ou se exacerba mais.

Isso levou o grupo a comparar os territórios das unidades de saúde, pois "essas construções sociais e culturais são constituidoras das subjetividades. . . Cada população de cada território acaba sendo atravessada e influenciada pelas questões daquele território, pelas questões daquele meio cultural, ainda que a gente viva na mesma cidade".

O grupo concluiu que são raras as situações atendidas que não incluem "alguma questão de gênero, ou pelo menos não entra implicado naquele sofrimento que a pessoa está trazendo". Contudo, explicou que dificilmente se recebe um pedido de ajuda em função de violências de gênero como demanda espontânea por parte das usuárias. Geralmente, são encaminhadas por algum profissional da mesma equipe ou de outro serviço que tenha identificado tais problemas, pois não costumam trazê-los como mote principal dos atendimentos, de modo que questões relativas à violência de gênero emergem depois na escuta, mascaradas pelo sintoma individual de uma mulher avaliada como depressiva, ansiosa, bipolar, histriônica, suicida. As participantes sublinharam a forma indireta como essa demanda é endereçada ao serviço, ou mesmo colocada em um lugar de pouca importância, e observaram que isso diz de uma percepção que as próprias mulheres têm de si mesmas: falam de seu próprio sofrimento de modo "meio mascarado", pois "isso não é o mais importante". O grupo concorda, exemplificando com o caso de uma senhora que relatava a hostilidade do filho com ela: "ela traz isso mas, logo em seguida, ela já se desdiz, assim, dizendo que 'ah não, mas ele está me ajudando, ele é um filho bom'...".

O termo "interseccionalidade" (Crenshaw, 2002) foi utilizado pelo grupo ao relacionar o gênero com outros marcadores sociais (raça/cor, faixa etária, classe social ou pertencimento a territórios periféricos, como os atendidos pelas unidades de saúde pesquisadas), em uma dinâmica que se constrói historicamente e afeta cada grupo social de uma forma particular. Foi mencionada, por exemplo, a grande quantidade de famílias em condições de maior vulnerabilidade que perderam homens assassinados em situações relacionadas ao tráfico de drogas. As mulheres atendidas “... não são as assassinadas, mas elas ficam com a dor ... dessas perdas todas" - um duro processo de luto que é muito determinado pela questão social, de acordo com o grupo e com a literatura (Moura et al., 2015; Souza, 2005).

\section{"Os homens também sofrem com isso"}

Visto que gênero é uma "categoria relacional" (Zanello, 2014, p. 44), o grupo suscitou espontaneamente diversas questões relativas aos homens. Identificou-se que um dos principais fatores de busca de atendimento é a sobrecarga no respectivo papel de gênero: quando um homem ou uma mulher "se cobra muito. . . ter que dar conta de algo que é imposto socialmente", isso gera sofrimento psíquico e um sentimento de "culpa muito forte". "Muito do acompanhamento é tentando desfazer essa culpa".

Segundo Zanello (2014), os valores de gênero narcisicamente importantes que traçam caminhos privilegiados de subjetivação, no Ocidente, estariam associados ao dispositivo amoroso e ao dispositivo materno para as mulheres e, para os homens, ao dispositivo da eficácia, baseado na virilidade sexual e laborativa. O grupo tinha exemplificado que os homens buscam atendimento quando perdem o trabalho e as mulheres, ao acabarem relacionamentos; contudo, no encontro seguinte, problematizou-se essa percepção ponderando que poderia ter sido "tendenciosa". Citaram casos de tentativas de suicídio, risco ou ideação suicida durante processos de separação: "acho que a maioria dos homens que eu já atendi vieram por demandas relacionadas à separação,. . .é uma coisa que mobiliza bastante o homem". Foi trazida “. . . a impressão que, para os homens, era mais dificil se colocar num papel de compromisso em relação ao casamento, mas que eles se tornavam muito mais dependentes do casamento do que as mulheres". 
Também recordaram-se de situações de feminicídio, “... que são muito relacionadas a um processo de separação e de intolerância à frustração". Feminicídio, de acordo com Barufaldi et al. (2017), é o assassinato de mulheres motivado por razões baseadas nas desigualdades entre os gêneros ou no intuito de obter poder, dominação ou controle sobre aquelas.

O grupo ainda observou a associação, no caso dos homens, entre comportamento violento e uso abusivo de álcool. Foram mencionadas falas recorrentes de usuárias da atenção básica que têm homens alcoolistas na família (situação prevalente entre a população mais idosa) e associam o consumo de álcool ora à agressividade ("ele é bom quando não bebe") ora à docilidade ("é daqueles que bebe mas não incomoda, ele vai dormir"; "o cara que se acalma quando usa álcool, a mulher compra exatamente para ele não encher o saco"). Destacou-se o abuso de drogas lícitas ou ilícitas como uma via de acesso ao cuidado em saúde para a população masculina: " não que venham só usuários de drogas homens, mas vários homens têm chegado pela motivação da questão do uso da droga".

Quanto ao perfil da população que busca atendimento em saúde mental na atenção básica, discutiu-se que:

... háalgum tempo atrás, era disparado senhorinhas de uma idade um pouquinho mais avançada, deprimidas. . . Hoje está diferente, têm vindo à procura pessoas muito jovens... O grupo de adolescentes tem tido uma demanda quase exclusiva de meninos; isso, há algum tempo atrás, não se imaginava.

Assim, o grupo considera historicamente recente a aceitação do atendimento pelos homens e relata que, nos atendimentos a esse público, "aparece muito essas coisas de o que é que se espera dos meninos". Algumas participantes disseram atender a poucos jovens do sexo masculino; outras contaram sobre experiências dessa escuta, que abrangeram, por exemplo, homens que sentem atração por homens. Considerando que as mulheres também falam da atração pelo mesmo sexo, o grupo julga que é muito mais difícil isso vir à tona quando se trata de um homem em atendimento, em virtude do "peso" dos estereótipos de gênero e da "rigidez" das características do estereótipo masculino, segundo as palavras utilizadas pelas participantes. Avaliou-se que "talvez seja até mais socialmente aceito ver duas meninas do que ver dois meninos", pois, no ideário masculino (que inclui os filmes de conteúdo pornográfico), é bastante frequente "ver duas mulheres juntas" como uma fantasia que excita os homens - e o inverso, não. Também se discutiu a invizibilização da bissexualidade masculina, a partir do caso de um menino de 14 anos cuja família "buscava encontrar um lugar para ele... ou ele é gay ou não ê". O grupo considera que "a bissexualidade tem muito mais preconceito do que a homossexualidade. . tudo que é mais indefinido tende a gerar um pouco mais de preconceito".

\section{"Várias gerações de mulheres cuidadoras"}

O primeiro caso trazido no encontro do grupo já evocava a naturalização dos papéis de gênero, que denota parâmetros desiguais sobre maternidade e paternidade e atribui a responsabilidade pelo cuidado sempre para o lado do feminino. Era o caso de “. . . uma usuária ... que se sente muito pouco empoderada para trabalhar com o companheiro as questões de divisão de tarefas da casa, do cuidado com os filhos e tal".

Exemplificou-se a naturalização da divisão social entre os papéis feminino e masculino:

. . . hoje, em dois atendimentos, veio essa questão. . . A primeira foi da mãe falando da filha de oito anos, em que ela dizia que a menina limpa a casa porque é papel dela, de menina, já tem que aprender desde cedo; que ela, quando tinha a idade da filha, já... ajudava a mãe em tudo. Então, trazendo como uma coisa bem naturalizada, porque o menino - o irmão - não tem nenhuma tarefa na casa. E a outra situação, que dai é uma situação de violência, de ciúme, assim, em que o marido diz "então tu tem que sair de casa". Mas ela não está traindo e, ... numa posição meio obedecendo, "se ele diz, então eu tenho que sair".

Essa divisão foi destacada e observada também nos próprios serviços de saúde:

... nós somos psicólogas mulheres também e, no posto, ... a maioria dos profissionais são mulheres... Isso também diz um pouco do lugar de cuidadora como um lugar de mulheres, da gente como psicólogas, e essa coisa da conversa associada mais 


\section{à. . . mulher também. Historicamente. . tem mais médicos homens. ${ }^{1}$}

Portanto, em ambas as falas, os homens aparecem em uma posição de autoridade, enquanto as mulheres se ocupam do cuidado - seja de si, do outro, da família, da casa ou de aplacar o sofrimento masculino. O grupo percebe que a naturalização do cuidado como inerente à mulher resulta em "um desreconhecimento do fazer feminino, muito grande, que a gente por vezes também não se dá por conta".

No cuidado dos filhos, mais especificamente, foi mencionada a ideia de "obrigação" traduzida pela afirmação "isso é da mãe", bem como pelo clichê "foi tu que quis ter esse filho, então, agora tu que dá um jeito", que ainda carrega o pressuposto de que a mulher engravida apenas por vontade própria. Em oposição, a ideia de "surpresa" é referida quando o pai realiza algum cuidado com os filhos, pois "isso não é do pai". No grupo, houve identificação com esses elementos tanto em suas vidas pessoais quanto na escuta das usuárias: "para as mulheres, não tem nenhuma exaltação, nenhum valor agregado a isso. .. Os homens fazem uma coisa, e eles são excelentes pais; a mulher faz uma coisa de 'errado' e daí já é um desastre de mãe". Uma vez que a maternidade é tomada como uma questão identitária para as mulheres, de uma maneira que a paternidade geralmente não envolve os homens, a diferença entre os parâmetros da maternidade e da paternidade produz uma invisibilidade não só dos cuidados exercidos por mulheres, como também das omissões praticadas pelos homens quanto aos filhos $\mathrm{e}$ seu acompanhamento em saúde:

. . . eu vejo essa ausência do pai muitas vezes... ou até, quando se insere, como se insere essa figura masculina?. . quando a mãe não está tão presente, a cobrança tanto da equipe quanto da família de que "bom, essa criança tem essa dificuldade porque essa mãe não está presente", sendo que o contrário já é super naturalizado. Tem [um menino] que eu acompanhei um tempão, e o pai eu conheci no final só, porque nunca consegui que o pai faltasse o trabalho [para vir à consulta com a psicóloga]. Porque. . a mãe pode faltar o trabalho pra vir, o pai não pode. De atendimento de crianças, é bem forte isso, mesmo quando são casos graves.

Ainda sobre essa problemática, o grupo referiu obstáculos no acesso ao mercado de trabalho e à educação infantil, o que retroalimenta a divisão dos papéis, pois mulheres que se tornaram mães "às vezes, nem são demitidas, mas toda a situação vai conduzindo para que a mulher siga sendo a cuidadora principal". Por exemplo, as mulheres atendidas na atenção básica geralmente "ganham um salário baixo, então uma creche particular é acima do salário"; por sua vez, os serviços públicos de educação infantil, por serem escassos, estabelecem critérios de acesso que não são adequados, como refere o trecho de narrativa a seguir:

A gente fez uma discussão assim em uma escola infantil. Como era uma mãe que não trabalhava fora (fazia faxina no condominio onde mora), a escola disse: "não, as vagas são para as mães que trabalham fora". Então, ela nunca ia poder trabalhar.

No segundo momento do grupo focal, as participantes problematizaram o acesso à educação infantil na instituição em que trabalham, momento em que algumas ficaram surpresas ao saberem que só as mães funcionárias tinham esse direito - como se os homens não tivessem filhos, apenas as mulheres. Entendeu-se essa priorização por esse direito ter sido adquirido justamente para que as mulheres pudessem trabalhar, porém, explicitou-se o paradoxo: ao passo que viabiliza que as mães trabalhem, reforça a ideia do cuidado dos filhos como tarefa exclusiva das mães.

\section{"Aquele desejo de constituir uma família a qualquer custo"}

Ao longo dos anos, foram percebidas mudanças em relação às necessidades em saúde mental das

\footnotetext{
1 "Para uma melhor compreensão do trabalho de cuidar é interessante analisar a distinção feita entre as palavras inglesas to care (cuidar) e to cure (curar) que traduzem historicamente a constituição do saber/poder médico que separa as atividades dos cuidados da vida (preventivos) com aquelas ligadas 'a reparação instrumental do corpo doente' (curativos). Isso distingue também os saberes, separando aqueles ligados ao cuidar, os quais geralmente as mulheres dominam, daqueles ligados ao reparar, cujo domínio está com a ciência médica .... Essa separação desvaloriza o cuidar em si, expurgando-o do campo médico profissional e restringindo-o ao campo do privado, afetivo, familiar, logo, do não profissional" (Scavone, 2005, p. 104, grifo da autora).
} 
mulheres atendidas. Entre adultas e idosas, poucas não referem histórico de abuso sexual. Quando o adoecimento envolvia questões com o corpo ou quadros psiquiátricos cronificados, "sempre tinha uma história de abuso sexual bem marcada" que, depois de muito tempo em acompanhamento, puderam ser verbalizadas. Elas nunca tinham falado para ninguém por "receio de que não iam acreditar ou que iam achar que foi provocado [por elas] de alguma forma"; ou contaram, mas o abuso não foi reconhecido ("minha mãe pediu para eu ficar quieta"), caso em que se soma o "sofrimento de não terem tido esse apoio". Atualmente, contudo, o grupo nota diferenças em relação à compreensão e à condição de silenciamento do abuso, visto que intervém em casos de adolescentes, pré-adolescentes e crianças com suspeita de abuso sexual, inclusive em ações intersetoriais com a escola e o Conselho Tutelar.

A naturalização e a reprodução da violência física e sexual, tanto intrafamiliar como externa à família, foi um dos temas abordados. Foi relatado o acolhimento de uma mulher machucada com o filho de dois anos no colo: seu marido tinha lhe dado um soco na cabeça. Esse menino, que "agora já está com três, quatro anos, já diz que vai bater na $m a \tilde{e}$ ". Quanto à violência conjugal, o grupo evidencia que hoje há uma maior rede de apoio do Estado para enfrentá-la, mas também uma tendência dos profissionais a questionarem as usuárias dos serviços: “como é que, apesar de tudo, ela segue com essa pessoa?". Observam que a dependência econômica do marido já não é o fator principal para que as mulheres não se separem, mas sim um certo "ideal de família - 'não tive família, não tive pai, mãe, irmãos' -, então, aquele desejo de constituir uma família a custo de qualquer coisa".

Embora a família siga tendo esse peso na vida das mulheres, o casamento já não aparece como necessariamente excludente ou limitador de outros papéis sociais. Ressaltou-se que, antigamente, a mulher que optasse "por trabalhar, ser uma mulher independente, morar sozinha, não poderia ser uma mulher com filhos nem casada; era uma coisa ou outra". Exemplificou-se com o caso de uma idosa que reside com o marido, com quem não mantém uma relação conjugal há anos:

... ela gostava muito do trabalho dela e, quando voltou da licença casamento, foi demitida, porque naquela época os chefes demitiam as mulheres casadas. .. Ela trabalhou numa loja de tecidos..., era muito reconhecida, e até hoje é muito saudosa.

Entretanto, a maternidade segue sendo um limitador, sobretudo no que diz respeito ao trabalho: "principalmente na iniciativa privada, as mulheres têm filhos, voltam da licença e são demitidas ainda, em muitos locais".

\section{"Por que o homem acha que pode usar uma mulher como se ela fosse um objeto?"}

Foi relatado que, em uma oficina sobre estereótipo de gênero realizada com o $6^{\circ}$ ano da escola do território de uma unidade de saúde,

. . as meninas trouxeram o preconceito dos professores e diretores da escola com relação à roupa. ..: "se a gente vem de saia curta, daí falam que a gente é vagabunda, a gente não pode isso, não pode aquilo". . . E os meninos. ... "se eu me visto com uma calça larga, eu já sou ladrão". É uma coisa meio que para um outro lado assim, de ser incitado a ocupar um lugar de empoderamento pela via da criminalidade.

Ou seja, há um maior controle sobre os corpos e os comportamentos das meninas, pois as mulheres são vistas como objeto do desejo do outro, do homem, o que restringe suas possibilidades de ocupar um lugar de sujeito de desejo. Complementar a essa noção, o estereótipo de "ladrão" diz da construção social da masculinidade por meio do poder e da agressividade, mas diz também da associação imaginária historicamente construída entre pobreza e periculosidade (Santos \& Nardi, 2018; Souza, 2005).

Também foi trazido um exemplo de outra escola da região, a partir do relato de uma adolescente atendida, o qual impressionou o grupo:

... uma brincadeira entre colegas em que amarraram uma colega dela numa cadeira e começaram a brincar, e os meninos ir passar a mão. . . estavam as meninas envolvidas e todo mundo envolvido, e ela e um outro colega foram contra aquela situação. . . desamarraram a menina, porque a menina. . . percebia que já tinha passado do ponto da brincadeira, mas não estava conseguindo cortar aquilo ali. Daí ela foi lá, ela e o colega, e tiraram a menina da cadeira e tal, $e$ 
do quanto aquilo foi recebido pelos colegas como um radicalismo - "está cortando o barato", "que chata", . . . "feminazi" - porque traz essas questões à tona. . . Até a menina - que acho que é bem comum também - dizer "não, era só uma brincadeira, não fica assim, eu estou bem"e tal.

As duas situações relatadas mostram como uma violência pode ser "legitimada pela forma como se dão as relações de gênero", ideia que levou o grupo a se interrogar: "Por que é que o homem acha que pode usar uma pessoa como se ela fosse um objeto?". No caso dos colegas que desamarraram a menina, chamar sua atitude de "radical" individualiza a questão, enquanto, na verdade, a atitude é de desnaturalização de um processo construído socialmente. Assim, deslegitima-se um discurso que tenta desfazer - nesse caso, literal e simbolicamente - as amarras da opressão. O grupo atribui a intolerância tanto ao comportamento de quem não tolera a opressão quanto de quem não tolera a mudança, isto é, a desnaturalização das práticas. No entanto, "a reflexão, a busca pela transformação, ela precisa estar presente. . . porque coisas como essa ainda continuam acontecendo: uma menina ainda continua sendo amarrada!".

\section{"Maternidade compulsória"}

Foi relatado o caso de uma usuária que foi estuprada por um desconhecido, apresentou sintomas graves após o trauma e teve uma gestação decorrente dessa violência sexual, o que desencadeou novas violências:

Depois de dois meses. . sozinha, sem sair de dentro de casa, de uma coisa compulsiva de tomar banho, limpar a casa. . . não conseguiu conversar com ninguém, até que chega na unidade [de saúde] já grávida. Soube que estava grávida porque teve um sangramento e acabou indo em alguma emergência, e o profissional que a atendeu ficou muito feliz por ela estar grávida, cumprimentou-a pela gestação, e ela não conseguiu falar disso e foi embora. $E$ aí foi na unidade no outro dia.

O caso mobilizou várias falas relacionadas ao caso: "é maternidade compulsória: as mulheres só são felizes se forem mães!. . . Ele não consegue escutar outra coisa que não seja a felicidade na maternidade. ... Zanello (2016) caracteriza a maternidade como construção histórica e o instinto materno, como um discurso ideológico, destrinchando a relação (não necessária) entre capacidade de procriação e maternagem, habilidade esta que pode - ou não - ser desenvolvida em qualquer pessoa. Então, após o estupro, a usuária passou por uma

. . . verdadeira peregrinação, então, para conseguir o aborto legal. . . As instituições também estão organizadas e funcionando nessas lógicas. . Ainda é negado um direito que, em tese, está escrito na legislação. . . mas que, no momento da concretização, isso é tão difícil.

Dios (2016) demonstra os obstáculos enfrentados pelas brasileiras que se encontram nessa situação, alguns dos quais foram mencionados pelo grupo, como o preconceito e a questão de a mulher "ter que provar" que sofreu violência sexual. Apesar das tentativas de excluir a possibilidade de abortamento legal da legislação brasileira, às quais o grupo fez alusão, nesse caso, a usuária foi bem acolhida no hospital e teve o procedimento realizado. O hospital informara que, atualmente, não tem recebido casos da atenção básica pelo fluxo de encaminhamento do aborto legal, o que o grupo atribui ao fato de que "poucas chegam [ao posto de saúde] e dizem 'eu quero abortar'; elas geralmente vão procurar outros meios. . Ainda chega muito depois de ter acontecido o aborto".

Quanto aos casos em que o aborto está proibido, o grupo narrou que:

No posto, já aconteceu várias vezes de. . uma mãel gestante já estar manifestando que não quer [ter o bebê], e de eu ser chamada para pensar junto uma orientação: "olha, qual é o jeito mais seguro dessa pessoa procurar, já que ela vai procurar?" De dizer "olha, o melhor é tu fazer uso de medicamento, não fazer uso de agulha, de não sei o quê"... Os profissionais ficam se confrontando com a sua moralidade também, com a coisa da ilegalidade, é que nem com usuário de droga. Assim, tu sabe que a pessoa vai usar... É muita hipocrisia... [Acontece] de pedirem ajuda da psicologia. . . para falar sobre isso com. . . a paciente, porque acho que não querem assumir o lugar de que estão incitando o aborto.

Outras participantes opinam que "hoje até está um pouquinho mais tranquilo, porque está nos 
manuais de medicina interna, tem no site da OMS [Organização Mundial da Saúde] formas de [abortar a gestação]... Mas ainda é um tabu....". Então concluem que, se os cuidados em saúde direcionados à maternidade já envolvem muita violência contra as mulheres pelo caráter estrutural dessa violência, “. . . imagina em relação ao aborto?".

\section{"Novas formas de exercício da sexualidade"}

As vivências de gênero e sexualidade desviantes da norma frequentemente resultam em necessidades em saúde mental. Foram citados muitos casos de mulheres homossexuais e um caso de um menino transexual, reproduzido a seguir:

... uma menina de sete anos que quer ser menino, já cortou o cabelo, já se veste de menino. ... a história dessa criança, apesar do contexto, tem sido muito tranquila: a escola está lidando bem, a família está lidando bem, dentro do que é possível.

Foram relatados fragmentos do acompanhamento psicológico:

Ela disse...Ele!"Doutora, quando eu tinha três anos, aconteceu uma coisa assim na minha cabeça, não sei o que que foi, virou tudo!". . . Disse para chamar de "ela" enquanto não mudar o nome oficialmente, porque eu perguntei. "Eu passei a semana toda pensando sobre isso, então eu acho que eu quero ser menino mesmo, né? Adorei a nossa conversa!"

Em termos de processo de decisão, a criança chegou para atendimento com muita clareza: "de já ter escolhido um nome, de querer trocar de escola, ir para uma outra escola com aquele outro nome, de se interessar por conhecer outros trans". Ressalta-se que essa identificação, na infância, com um gênero diferente daquele que lhe foi socialmente atribuído, "no processo de desenvolvimento, isso aparece. . . essa é a história da maioria dos trans" que buscam atendimento após a maioridade.

No caso relatado, a mãe verbalizava: "Quando eu era criança, também queria ser menino, não pelo ser menino, pela liberdade que os meninos tinham, pelas coisas que os meninos podiam fazer e que eu não podia". Portanto, ela traduz a ideia de que uma mulher não teria a liberdade de fazer o que os homens fazem, conforme o trecho de narrativa a seguir:

E muitas mulheres que se experimentam em outras coisas que querem são vistas com muito preconceito, assim, no bairro, pelas vizinhas, pelas senhoras, que têm um outro estilo de se vestir, que levam a sua vida sexual de um outro jeito, acabam tendo muito que sair das suas famílias de origem ali-porque tem essa coisa, no território da unidade [de saúde], de as pessoas viverem três, quatro gerações ali.

Comentou-se o caso de uma adolescente que sente atração por ambos os gêneros:

. . . ela transita por isso de forma tranquila, sem inclusive se autodefinir. . Ela diz: "eu não sei se eu sou lésbica, eu não sei se eu sou bi, eu não sei se eu sou homo, mas enfim, eu gosto de meninas e meninos".

Lembrando-se de casos semelhantes, o grupo notou que "não é só na adolescência". "Hoje em dia, existe uma possibilidade maior ... para eu me identificar com algo que não seja relacionado, ... pelo menos, formalmente ou conservadoramente, com o meu gênero. Porque tem mais visibilidade". Considerou-se positivo que esse debate esteja posto socialmente, no sentido de possibilitar expressões como essa sem transformá-las necessariamente em sofrimento. Um ex-paciente “. . que, hoje, deve ter uns 27 anos, e tinha cinco na época, dizia 'eu quero ser uma menina' na sessão. Só que isso, há 22 anos atrás, era muito mais difícil de estar colocado". Cogitaram que, à época, isso “. . . provavelmente era escutado como 'eu sou homossexual. . ., então possivelmente ele não se tornou uma menina. Ou se tornou, eu não sei".

Quanto ao momento histórico atual, foi feita a seguinte reflexão: “. . . as representações, os papéis sociais atribuídos [a homens e mulheres], com certeza permanecem os mesmos, mas eu acho que deve estar surgindo algo aí que a gente, daqui a pouco, vai ver mais teorização em cima". O grupo diz ter aprendido com os adolescentes atendidos sobre o uso da escrita como "uma transgressão do gênero, um não-gênero", ao flexionar o gênero das palavras utilizando o “Xinvés do O ou do A" - por exemplo, todxs para se referir a todas as pessoas. E surgiram questionamentos: 
... como será que essas questões de gênero. . . vão se colocar numa geração de adolescentes, por exemplo, que atualmente trazem uma outra forma de exercício da sexualidade?. . Será que isso que a gente já tem mais instituído, mais construído, ainda vai continuar fazendo sentido?

Então, foram trazidos os casos de duas jovens de vinte anos:

Uma também tem essa coisa de ser bi mas não se nomear assim. . eu vejo que o sofrimento passa muito por, quando ela começou a se envolver com alguém, de se culpabilizar por não ficar tranquila de ver a pessoa ficando com outras pessoas. Porque. . . todo mundo fica com todo mundo ali naquele grupo. . E daí ela sofrendo com o processo de estar se envolvendo e perceber que deveria ser mais desapegada, digamos assim, como se essa desconstrução. . . estivesse causando um outro problema para ela. E outra, que tem uma situação de automutilação, já tinha um diagnóstico anterior de borderline, uma situação de se colocar sempre em situações muito limites. . ., se relaciona com meninas $e$ meninos, mas estava namorando uma menina, de levar ao extremo a coisa de não querer estar em um padrão, de tipo "bom, então eu fico com o melhor amigo da minha namorada, ela fica com o meu melhor amigo, e vamos ver o quanto a gente suporta". E eu tenho percebido que isso tem sido um novo problema.

A psicóloga conta que tem trabalhado com ambas questões como:

... do autocuidado, do cuidado com o outro, de ir pactuando coisas, de ir construindo essas regras na própria relação, de ir construindo acordos. $E$ isso é super difícil, porque daí parece que não pode ter nada de regra ... Mas a regra combinada, acordada, construída, ganha um sentido.

O grupo deixou alguns questionamentos em suspenso. Quando se abandona esse referente do padrão externo, instituído e questionado, que critérios podemos criar, para que uma relação ganhe consistência? $\mathrm{O}$ que se institui cada vez que ocorrem processos de mudança? O que virá a se institucionalizar?

\section{“O hospital tomou como uma afronta o empoderamento da mulher"}

Foram trazidas, ainda, questões relativas ao acompanhamento da saúde das mulheres na atenção básica. As gestantes, por exemplo, muitas vezes desconhecem seus direitos e somente no acompanhamento pré-natal passam a saber que têm direito, por exemplo, a acompanhante no parto, a visitar o hospital em que ocorrerá, a construir plano de parto - desconhecimento que deixa as mulheres mais vulneráveis a violências no atendimento à saúde. No entanto, o grupo considera que esse empoderamento por meio do saber tampouco garante um fator protetivo, como no caso de uma usuária que chegou no centro obstétrico com seu plano de parto

... e pegou um plantão do hospital que. . . tomou como uma afronta aquilo, e aí sofreu uma violência obstétrica por estar sabendo as coisas. Tem profissionais do posto que já me disseram: "eu tenho muita dificuldade de orientar a construir plano de parto, porque tenho medo que ela chegue lá e seja violentada; ela vai ser menos violentadase chegar passiva". Esse foi um conflito que a gente viveu com dois casos. . bem graves: a mulher ficou muito tempo sem conseguir sair nem falar com ninguém.

Também foi mencionada a situação de um casal que tinha planejado ter filhos por parto vaginal mas, por uma complicação na véspera, o médico informou que não seria possível e indicou a cesariana. Ainda que a mulher tivesse acatado a indicação médica, o marido não aceitou e tentou obrigá-la a trocar de médico, causando um sério conflito entre os três. Logo que nasceu, o bebê teve um problema de saúde de pouca gravidade, pelo qual o marido culpabilizava a esposa injustificadamente, dizendo: "se tivesse sido parto normal, isso não teria acontecido?". Embora o grupo também tenha acesso a relatos bastante positivos sobre os partos realizados em hospitais, evidenciou-se o desrespeito às decisões das mulheres sobre o próprio corpo, tanto pelos profissionais da saúde quanto pelos familiares.

Quanto às puérperas, o grupo percebe "um discurso muito forte do 'tem que amamentar", chamado jocosamente de "patrulha da amamentação". Para ilustrá-lo, foi descrita uma cena de uma mãe adolescente na unidade de saúde: 
. . . sentada na cadeira com seu bebê, e toda a equipe de enfermagem na volta: "faz assim, faz assado". De me sentir mal. "Não, tu vai conseguir, vou na tua casa". Claro, tu pode fazer isso com cuidado e realmente apoiar, mas não porque tem que. . . Muitos profissionais, por um lado, acho que sabem pouco no sentido de orientar a amamentação, ajudando a encontrar caminhos possíveis mas assumindo a possibilidade de não amamentar. Porque, às vezes, tu dizer que ela pode não amamentar ajuda ela a amamentar, inclusive! ... Ou as pessoas assumem a tendência de "tá, é dificil, taca [suplemento alimentar] ". Mas, na atenção primária, não tem muito essa tendência, às vezes já chega por qualquer outra via de atendimento . . . Eu vejo meio que os dois extremos, . . que é não suportar o processo de construir um pouco a amamentação, o processo de cada pessoa, de não ter um jeito certo ou errado.

A partir dessas questões, o grupo se questionou sobre o papel dos profissionais da saúde e do psicólogo em específico, pois percebem que a desigualdade de gênero também constitui um viés nas teorias e técnicas que embasam o trabalho do psicólogo e das instituições de saúde:

... a execução das políticas públicas, obviamente, se encontra atravessada também por essa construção cultural, ideológica, [que] acaba sendo determinante inclusive no momento do estabelecimento dos diagnósticos. Para as mulheres, por exemplo, chorar é muito fácil de ligar com. . . depressão: "está muito chorosa, está deprimida". Isso é mais ou menos esperado e até visto como banal. O choro, em um homem, ... repercute nas equipes de uma outra forma. . . Houve um tempo em que as mulheres foram encarceradas nos hospícios por se colocar na vida e na sociedade - pelo menos tentar se colocar. . . - de um modo que não era o esperado para o feminino, e isso ser lido como um sintoma de doença mental, não como uma construção social. Quando as mulheres começaram a tentar não obedecer aos maridos, enfim, ir para o mercado de trabalho. . . O marido queria se livrar daquela mulher para conseguir outra, encarcerava no hospício.

O grupo lembrou, inclusive, que a categoria "adultério" encontra-se documentada como motivo de antigas internações de mulheres no Hospital Psiquiátrico São Pedro. Isso demonstra que o debate de gênero tem desafiado e transformado alguns conhecimentos já instituídos em diferentes linhas da psicologia (Brasil \& Costa, 2018; Martins \& Poli, 2018; Narvaz \& Koller, 2006). Em casos como o da criança transexual de sete anos de idade, as participantes têm apresentado iniciativas de busca de apoio técnico:

... a gente já acompanhou a situação da cirurgia de troca de sexo de um jovem adulto, mas criança bem pequena assim nunca tinha atendido. . . então até tive que fazer uma discussão de caso com o pessoal da universidade para entender um pouco o que é que eles têm pensado.

O grupo pondera que as teorias - inclusive as que embasam as práticas psi - foram produzidas dentro de determinados paradigmas, reproduzindo e reforçando referenciais da cultura de certo momento histórico, e se atualizam de diferentes formas. Portanto, as participantes julgam fundamentais as atualizações produzidas a partir da prática, considerando a problematização de gênero, bem como os espaços coletivos de reflexão e trocas para compartilhamento e qualificação do trabalho do psicólogo. Afinal, como a execução das políticas públicas é atravessada pelas questões de gênero, conforme observado pelo grupo,

. . . persiste, no campo da saúde mental, uma hegemonia das práticas e do discurso centrado nas questões biomédicas e a invisibilidade das diferenças de gênero. Torna-se urgente a revisão desses paradigmas de modo a introduzir novos enfoques que permitam compreender as necessidades de saúde da população feminina e intervir de forma adequada (Negrão et al., 2015, p. 43).

\section{Considerações finais}

O grupo focal foi composto por psicólogas inseridas em equipes de saúde multiprofissionais que atuam na rede intersetorial a partir da atenção básica, em Porto Alegre, em 2017. A metodologia do Grupo Focal Narrativo permite, simultaneamente, pesquisar e intervir sobre um coletivo singular. Consideramos uma possível limitação do estudo a homogeneidade do grupo 
em relação a gênero, profissão e área de atuação, o que resultou em significativa concordância entre as participantes, ainda que a discussão coletiva tenha favorecido o compartilhamento e a problematização de saberes. O próprio grupo pesquisado sugeriu contemplar outras categorias profissionais em futuros estudos.

Os núcleos argumentais da narrativa coletiva expõem o que a escuta dessas psicólogas da atenção básica permite identificar como formas comuns de expressão do sofrimento psíquico das mulheres e como essas profissionais relacionam a desigualdade de gênero com os processos de produção de saúde-adoecimento-cuidado. Assim, evidenciou-se não só a realidade atual do território vivo, mas também saberes e práticas produzidos nas experiências de saúde pública no Brasil que são de suma importância para o desenvolvimento da psicologia.

Ademais, foram apontadas questões que não puderam ser aprofundadas nesta oportunidade por não serem o foco da pesquisa, como a produção das masculinidades, a questão racial, entre outras, que também têm relação com as demandas em saúde mental das mulheres. Contudo, entendemos que a problematização da escuta psi sempre contribui para que se possa estabelecer os nexos necessários entre o sofrimento psíquico e as desigualdades sociais em saúde.

\section{Referências}

Barata, R. B. (2009). Como e por que as desigualdades sociais fazem mal à saúde. Fiocruz.

Barufaldi, L. A., Souto, R. M. C. V., Correia, R. S. B., Montenegro, M. M. S., Pinto, I. V., Silva, M. M. A., \& Lima, C. M. (2017).Violência de gênero: Comparação da mortalidade por agressão em mulheres com e sem notificação prévia de violência. Ciência \& Saúde Coletiva, 22(9), 2929-2938. https://doi.org/10.1590/1413-81232017229.12712017

Brasil, M. V., \& Costa, A. B. (2018). Psicanálise, feminismo e os caminhos para a maternidade: Diálogos possíveis? Psicologia Clínica, 30(3), 427-446. http://doi.org/10.33208/PC1980-5438v0030n03A02

Butler, J. (1990). Actos performativos y constitución del género: Un ensayo sobre fenomenología y teoría feminista. In S. H. Case (Org.), Performing feminisms: Feminist critical theory and theatre (pp. 296-314). Johns Hopkins.

Campos, C. M. S., \& Bataiero, M. O. (2007). Necessidades de saúde: Uma análise da produção científica brasileira de 1990 a 2004. Interface, 11(23), 605-618. https://doi.org/10.1590/S1414-32832007000300014

Crenshaw, K. (2002). Documento para o encontro de especialistas em aspectos da discriminação racial relativos ao gênero. Revista Estudos Feministas, 10(1), 171-188. https://doi.org/10.1590/S0104-026X2002000100011

Dios, V. C. (2016). Da clínica da assistência à clínica da perícia: Sobre os serviços de aborto legal no Brasil. In V. Zanello \& M. Porto (Orgs.), Aborto e (não) desejo de maternidade(s): Questões para a Psicologia (pp. 81-99). Conselho Federal de Psicologia.

Franco, M. H. C., Fajardo, A. P., \& Mello, E. D. (2020). Escutando Mulheres: questionamentos oriundos da psicologia na saúde pública. In A. Z. Branchi, E. Rodrigues \& T. F. de Castilhos (Orgs.), Residência Multiprofissional no SUS: Formação e a produção de saúde (1a ed., p. 145-161). Hospital Nossa Senhora da Conceição.

Martins, A. C. B. L., \& Poli, M. C. (2018). Transexualidade e norma sexual: A psicanálise e os estudos queer. Revista Subjetividades, ed. especial, 55-67. https://doi.org/10.5020/23590777.rs.v18iEsp.6535

Merhy, E. E. (2002). Saúde: A cartografia do trabalho vivo. Hucitec.

Miranda, L., Figueiredo, M. D., Ferrer, A. L., \& Onocko-Campos, R. T. (2008). Dos grupos focais aos grupos focais narrativos: Uma descoberta no caminho da pesquisa. In R. T. Onocko-Campos, J. P. Furtado, E. Passos \& R. Benevides (Orgs.), Pesquisa avaliativa em saúde mental: Desenho participativo e efeitos de narratividade (pp. 249-77). Aderaldo \& Rothschild.

Moura, E. C., Gomes, R., Falcão, M. T. C., Schwarz, E., Neves, A. C. M., \& Santos, W. (2015). Desigualdades de gênero na mortalidade por causas externas no Brasil, 2010. Ciência \& Saúde Coletiva, 20(3), 779-788. https://doi.org/10.1590/1413-81232015203.11172014

Narvaz, M. G., \& Koller, S. H. (2006). Famílias e patriarcado: Da prescrição normativa à subversão criativa. Psicologia \& Sociedade, 18(1), 49-55. https://doi.org/10.1590/S0102-71822006000100007

Negrão, T., Vargas, R., \& Rodrigues, L. P. (Orgs.). (2015). Saúde mental e gênero: Novas abordagens para uma linha de cuidado (pp. 7-12). Coletivo Feminino Plural. 
Onocko-Campos, R. (2011). Fale com eles! O trabalho interpretativo e a produção de consenso na pesquisa qualitativa em saúde: Inovações a partir de desenhos participativos. Physis, 21(4), 1269-1286. https://doi.org/10.1590/ S0103-73312011000400006

Prefeitura Municipal de Porto Alegre. (2019). Estrutura. http://www2.portoalegre.rs.gov.br/sms/default. php?p_secao $=808$

Resolução no 466, de 12 de dezembro de 2012. (2012). Aprova as diretrizes e normas regulamentadoras de pesquisa envolvendo seres humanos. Ministério da Saúde.

Santos, H. B., \& Nardi, H. C. (2018). Entre o trabalhador e o vagabundo: Produção de masculinidades na história da saúde no Brasil. Temas em Psicologia, 26(4), 2299-2316. http://doi.org/10.9788/TP2018.4-21Pt

Scavone, L. (2005). O trabalho das mulheres pela saúde: cuidar, curar, agir. In W. Vilella \& S. Monteiro (Orgs.), Gênero e Saúde: Programa Saúde da Família em questão (pp. 101-111). Associação Brasileira de Saúde Coletiva, Fundo de População das Nações Unidas.

Schraiber, L. B., \& Mendes-Gonçalves, R. B. (1996). Necessidades de saúde e atenção primária. In L. B. Schraiber, M. I. B. Nemes \& R. B. M. Gonçalves (Orgs.), Saúde do adulto: Programas e ações na unidade básica (pp. 29-47). Hucitec.

Souza, E. R. (2005). Masculinidade e violência no Brasil: Contribuições para a reflexão no campo da saúde. Ciência \& Saúde Coletiva, 10(1), 59-70. https://doi.org/10.1590/S1413-81232005000100012

Teixeira, R. R. (2005). Humanização e atenção primária à saúde. Ciência e Saúde Coletiva, 10(3), 585-598.

Zanello, V. (2014). A saúde mental sob o viés do gênero: Uma releitura gendrada da epidemiologia, da semiologia e da interpretação diagnóstica. In V. Zanello \& A. P. M. Andrade (Orgs.), Saúde mental e gênero: Diálogos, práticas e interdisciplinaridade (pp. 41-58). Appris.

Zanello, V. (2016). Dispositivo materno e processos de subjetivação: Desafios para a Psicologia. In V. Zanello \& M. Porto (Orgs.), Aborto e (não) desejo de maternidade(s): Questões para a Psicologia (pp. 103-122). Conselho Federal de Psicologia.

Zanello, V., Fiuza, G., \& Costa, H. S. (2015). Saúde mental e gênero: Facetas gendradas do sofrimento psíquico. Fractal Revista de Psicologia, 27(3), 238-246. https://doi.org/10.1590/1984-0292/1483

\section{Marina Haase da Costa Franco}

Especialista em Intervenção Psicanalítica na Clínica com Crianças e Adolescentes pela Universidade Federal do Rio Grande do Sul (UFRGS). Psicóloga na Gestão do Trabalho, Educação e Desenvolvimento no Grupo Hospitalar Conceição, Porto Alegre - RS. Brasil.

E-mail: hmarina@ghc.com.br

(D) https://orcid.org/0000-0002-8595-0907

\section{Ananyr Porto Fajardo}

Doutora em Educação pela Universidade Federal do Rio Grande do Sul (UFRGS). Coordenadora do Curso Superior de Tecnologia em Gestão Hospitalar, Faculdade de Ciências da Saúde do Grupo Hospitalar Conceição, Porto Alegre - RS. Brasil. E-mail: fananyr@ghc.com.br

(1) https://orcid.org/0000-0002-5501-3795

\section{Priscila Abrahão Pereira Cardoso}

Especialista em Trabalho Social com Famílias e Comunidades pelo Domus - Centro de Terapia Individual, de Casal e Família. Psicóloga (técnica social) do Serviço de Atendimento Familiar (SAF) Floresta da Associação Intercomunitária de Atendimento Social (AICAS), Porto Alegre - RS. Brasil.

E-mail: priscilaapcardoso1@gmail.com

(1) https:// orcid.org/0000-0001-8510-5685 


\section{Eliana Dable de Mello}

Doutora em Educação pela Universidade Federal do Rio Grande do Sul (UFRGS). Membro da Associação Psicanalítica de Porto Alegre (APPOA) e do Instituto APPOA, Porto Alegre - RS. Brasil.

E-mail: elianamello3@gmail.com

(1) https://orcid.org/0000-0002-7984-4913

Endereço para envio de correspondência:

Hospital Nossa Senhora da Conceição. Av. Francisco Trein, 596, Centro Administrativo, $3^{\circ}$ andar, Gestão do Trabalho, Educação e Desenvolvimento, Bairro Cristo Redentor. CEP: 91350-200. Porto Alegre - RS. Brasil.

Recebido 11/06/2019

Aceito 05/03/2021

Received 06/11/2019

Approved 03/05/2021

Recibido 11/06/2019

Aceptado 05/03/2021

Como citar: Franco, M. H. C., Fajardo, A. P., Cardoso, P. A. P., \& Mello, E. D. (2021). Desigualdade de gênero e escuta psi de mulheres atendidas na Atenção Básica. Psicologia: Ciência e Profissão, 41, 1-15. https://doi.org/

$10.1590 / 1982-3703003225110$

How to cite: Franco, M. H. C., Fajardo, A. P., Cardoso, P. A. P., \& Mello, E. D. (2021). Gender Inequality and Psychological Listening of Women Attended in Primary Healthcare. Psicologia: Ciência e Profissão, 41, 1-15. https://doi.org/10.1590/1982-3703003225110

Cómo citar: Franco, M. H. C., Fajardo, A. P., Cardoso, P. A. P., \& Mello, E. D. (2021). Desigualdad de Género y Escucha de Mujeres que Procuran Atención Primaria. Psicologia: Ciência e Profissão, 41, 1-15. https://doi.org/ $10.1590 / 1982-3703003225110$ 